\title{
Independent café entrepreneurships in Klang Valley, Malaysia - challenges and critical factors for success: does family matter?
}

\begin{abstract}
This article investigates the challenges of Klang Valley's independent cafés at the entry stage, while also identifying their shared critical factors for success and their common practices. A total of five exemplar cases and two coffee industry experts were sampled in a two-phase qualitative approach. A list of eight challenges were identified and thematic analysiswas used to find four critical success factors essential to survive past the entry stage: (1) concept vs. strategies; (2) an extended notion of location selection; (3) building foundations; and (4) family factors and family life-cycle management. By understanding the critical success factors of the exemplar cafés, foodservice entrepreneurs can gain insights on how these factors could be incorporated into their business strategies to survive the entry stage. Moreover, by investigating Klang Valley's café culture, this study broadens the understanding of Klang Valley's destination characteristics, and provides practical and realistic implications that contribute to the development of Klang Valley through cultural and culinary tourism initiatives.
\end{abstract}

Keyword: Independent café; Entry stage; Entrepreneurship; Family factors; Coffee industry 